\title{
JOINT PROJECT SIMULTAN - SINKHOLE CHARACTERIZATION AND MONITORING WITH SUPPLEMENTING GEOPHYSICAL METHODS
}

\author{
Charlotte M. Krawczyk
}

GFZ German Research Centre for Geosciences, Telegrafenberg, D-14473 Potsdam, Germany, lotte@gfz-potsdam.de

\section{SIMULTAN Research Group}

http://simultan.gfz-potsdam.de

\begin{abstract}
The joint project SIMULTAN (Sinkhole Instability: integrated MULTi-scale monitoring and ANalysis) develops and applies an early recognition system of sinkhole instability, unrest, and collapse in Germany. The research approach combines structural, geodetic, geophysical, petrophysical, and hydrogeological mapping methods, accompanied by sensor development, multi-scale monitoring, modelling, and an information platform. Two focus areas are investigated in Germany, for which sinkhole unrest has been identified. The surveyed areas are representative of evaporitic sinkhole formation, and are highly relevant since located in densely populated areas.
\end{abstract}

Shear-wave reflection seismics enables high-resolution structural imaging of critical zones, while additional vertical seismic profiling (VSP) provides hints on subrosive zones by velocity analyses. Spatial detection thresholds for microseismic events were calculated using a combination of synthetic event signals and noise recorded in the field. Improvements of the detection and localization capability due to additional borehole stations and surface mini-arrays were investigated. The potential to detect mass dislocations in the upper subsurface is proven by repeated gravimetry and levelling campaigns, that are supplemented by microgravimetry. How combined direct-push and SIP-monitoring will characterize sufficiently the soil-water-interaction in the upper $40 \mathrm{~m}$ is still in the testing phase, but stable inversion schemes are yielded.

All these petrophysical parameters are fed into modelling and simulation studies that describe dissolution initiation and explain realistic collapse scenarios in the light of overburden strength. These shall support decision processes, and the cooperation with geological surveys will advance the development of sinkhole instability recognition systems.

\section{Introduction}

Scientific key questions in sinkhole research encompass the geophysical characterization of subsidence areas, the control of void evolution and sinkhole formation at depth, or if micro-earthquakes are precursors for larger rock fall or collapse events.

Close to surface, sinkholes manifest in a variety of ways, depending on both process stage and rate (Figure 1). While collapse structures occur rapidly and within a few minutes, continuous subsidence is observed in many sinkhole areas, that progresses slowly and for many years with only a few $\mathrm{mm} /$ year. Individual process components may be simple and can easily be understood, but the interaction of different processes ahead a collapse and precursor phenomena with different rates and dimensions impede full process understanding. In addition, the variability of controlling parameters and its consequences are not well understood. Therefore, multi-scale observation and integrated analyses are essential for early recognition systems, especially for shallow exploration in urban areas (Krawczyk and Dahm, 2011).

First steps were undertaken in Thuringia (Katzschmann et al., 2015) and Hamburg, where staggered faults and subsidence are observed on top of a salt diapir (Krawczyk et al., 2012). Such characteristics are also seen in Kansas (Miller et al., 2008) or Texas (McDonnell et al., 2007), where collapse structures were investigated with different geophysical methods. In Germany, combined approaches are rare (Gebregziabher, 2011; Wiederhold et al., 2008; Reuther et al., 2007) but receive growing importance (Wadas et al., in review). Combined seismic reflection-refraction measurements were tested in urban areas in Canada (Hunter et al., 2010). SIMULTAN therefore applies an integrated approach for sinkhole process understanding. 

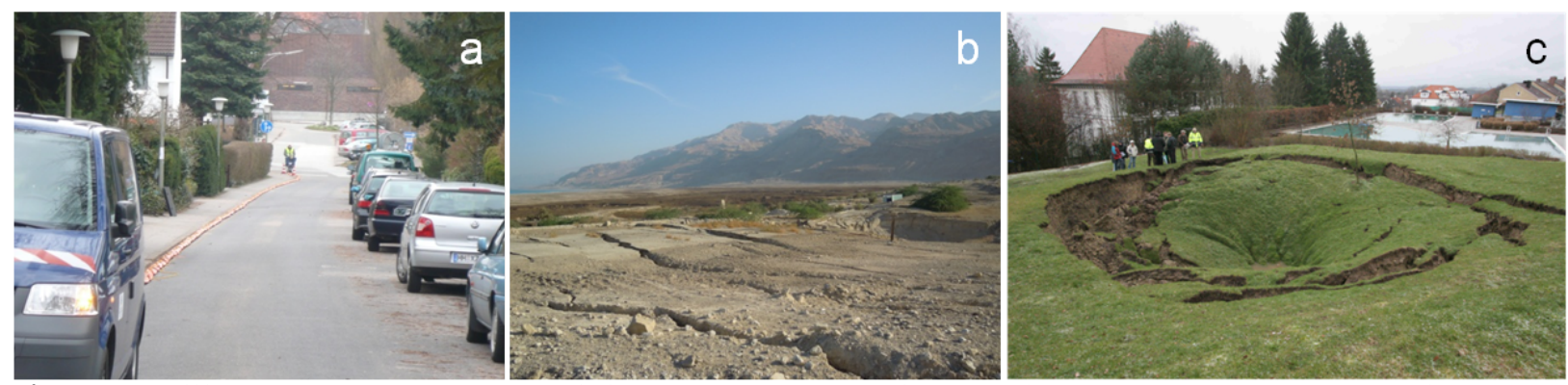

Figure 1. Different process stages of sinkholes: slow subsidence in Hamburg (a), developing fracturing at surface in Jordan (b), and a $10 \mathrm{~m}$ deep hole at collapse initiation in Northeim (c).

\section{Initial Position}

The local governments in Germany provide individual information and maps about areas of potential sinkhole hazard, but a collective hazard map does not exist. The sinkhole areas are generally located on top of salt highs in northern Germany, or within sulfate karst or carbonate karst, which is dominant in middle and southern Germany (Figure 2). Since urban population growths, and also growths towards and into sinkhole areas, the understanding of sinkhole occurrence and processes is of increasing relevance.

Depending on soil structure and the onset and evolution of the process, sinkholes can cause continuously growing subsidence of the Earth's surface (e.g., Flottbek/Hamburg; Ochtmisser Kirchsteig/Lüneburg) or collapse abruptly, thereby opening holes with diameters of 10th of meters (e.g., Schmalkalden and Tiefenort/ Thuringia, 2010; Quickborn/Schleswig-Holstein, 2010; Münsterdorf/Schleswig-Holstein, 2003-16). In Figure 2 the specific locations are marked, where also part of our research focuses. Further examples of sinkhole types can be found in Waltham et al. (2005). Both sinkhole types can cause large infrastructure damages (ca. 93 Mill. USD were spent by insurance companies in Florida in 2009; 38 Mill. USD were lost by the Arab Potash Company within 30 minutes by sinkhole-induced collapse in Dead Sea evaporation pans).

\section{Geophysical Surveying}

The research approach of SIMULTAN is structured in several components, that encompass geophysical field surveys, integrated analysis of data, model development, and simulations. Finally, we combine the information of past and ongoing activity with prognoses for possible sinkhole collapses, serving for knowledge transfer and decision processes. Our concept comprises interconnected work packages that investigate large- to small-scale phenomena and consider time-dependent data. These are presented in the following.

\section{Seismic Investigations}

To study near-surface subrosion structures, shear-wave reflection seismic profiling provides high-resolution structural depth sections in the focus areas Hamburg and Bad Frankenhausen (e.g., Krawczyk et al., 2012; Wadas et al, 2016). The seismic profiles were acquired with the

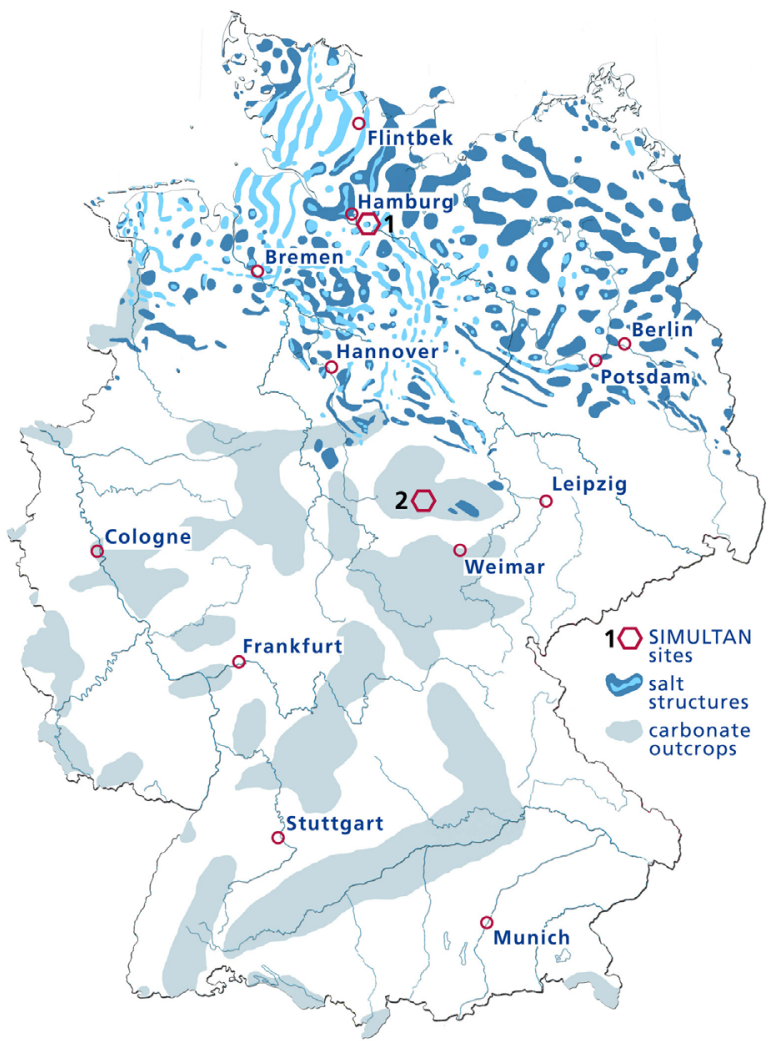

Figure 2. Simplified geological map of Germany showing areas that can suffer sinkhole hazard (modified after Krawczyk et al., 2015). In the north, salt is dominant, while in the middle and south carbonates crop out. Hexagons: working areas of SIMULTAN. 
horizontal micro-vibrator ELVIS developed at LIAG and a landstreamer equipped with horizontal geophones (for further technical details see Krawczyk et al., 2012, 2013). This setup allows for ca. $1 \mathrm{~m}$ vertical resolution in the uppermost $10 \mathrm{~m}$ subsurface, and 1-3 m further below.

The geological underground of Hamburg and Thuringia is characterized by soluble rocks of Permian age, especially Zechstein deposits. The various seismic lines gained show subrosion-induced structures to a depth of ca. $100 \mathrm{~m}$. While Hamburg is characterized by surface subsidence, slightly sagging sediments and a fault system at $80 \mathrm{~m}$ depth (Krawczyk et al., 2012), the Thuringian investigation area is rather finely fractured close to surface and exhibits collapse structures in the surrounding (Wadas et al., 2016, 2017). A common feature is identifiable in the velocity fields of both regions: the laterally and vertically varying seismic velocities and low-velocity zones. These presumably delineate areas of enhanced fracturing and upward migrating cavities. Borehole measurements corroborate the idea of high porosity and cavities by decreased specific electric resistivity and low shear-wave seismic velocities (Tschache et al., 2017).

\section{Micro-Seismic Monitoring}

The monitoring of the seismogenic characteristics of a study area can improve the description of its deformational behavior. Therefore, the setup of a quality-controlled monitoring network in Hamburg was performed. Due to the high ambient noise level in the urban environment in combination with the complex waveforms of these shallow events traditional detection and localization approaches often fail (Becker et al., 2017). Using a combination of synthetic event data utilizing information about the source mechanism of known sinkhole events and the local velocity model (Dahm et al., 2011) and ambient noise data recorded at the network stations, the spatial detection capability was investigated and triggering routines adjusted (Becker et al.,2017). In addition to routine localization approaches also stacking algorithms using characteristic functions of the waveforms are investigated. Here, an algorithm incorporating time shifts derived from synthetic STA/LTA (Short Time Average over Long Time Average) maxima improves the results when compared to traditional travel time stacking. The use of geophone surface mini arrays, in addition to improving the characterization of the noise field, also has the potential to better constrain the source localization (Becker et al., 2017).

Apart from compromising event detection and localization the ambient noise field can also be used to investigate possible changes of underground parameters and check the timing accuracy of seismic stations. From investigations of the ratio of the horizontal to vertical component of the ambient noise spectra (H/V method) a station specific diurnal and annual variation is observed which hints at variable noise sources but might also contain information about possible changes of physical subsurface parameters. If such developments are incorporated in monitoring systems, early recognition of underground movement is strongly enhanced.

\section{Gravity Repeats, GNSS, and Levelling}

The effect of Zechstein evaporite leaching in Thuringia is investigated with geodetic time-lapse observations. Figure 3 shows the monitoring network that has been set up. It consists of 15 gravity stations and additional levelling locations which cover the main sinkhole areas in the city of Bad Frankenhausen (Kobe et al., 2017; Kersten et al., 2017). Starting with the baseline survey in 2014, network points are monitored by quarterly campaigns. The last three years provide gravity acceleration changes ranging between $0-15 \mu \mathrm{Gal}$, accompanied by subsidence of 0-15 $\mathrm{mm}$ indicated by levelling (Kobe et al., 2017).

To monitor the long-term stability of the gravity reference an absolute gravimeter point was established in 2015 (Kersten et al., 2017). Furthermore, micro-gravimetric measurements provide a structural model of the area necessary for the interpretation of geodetic signals.

Additionally, semi-annually GNSS (Global Navigation Satellite System) campaigns provide estimates for the monitored network locations. Therefore, a star-like network has been established and is fixed at the local reference station (c.f., station SL03 in Figure 3). The local reference station is tied to the national SAPOS (Satellite Positioning Service, Germany) network with the Geodetic Datum of December 1, 2016. It gives evidence that deformation is limited to local subsidence areas. Displacements of GNSS network points are obtained with respect to the local reference station.

Accuracies of the final monitoring network coordinates, processed with combined GPS and GLONASS 


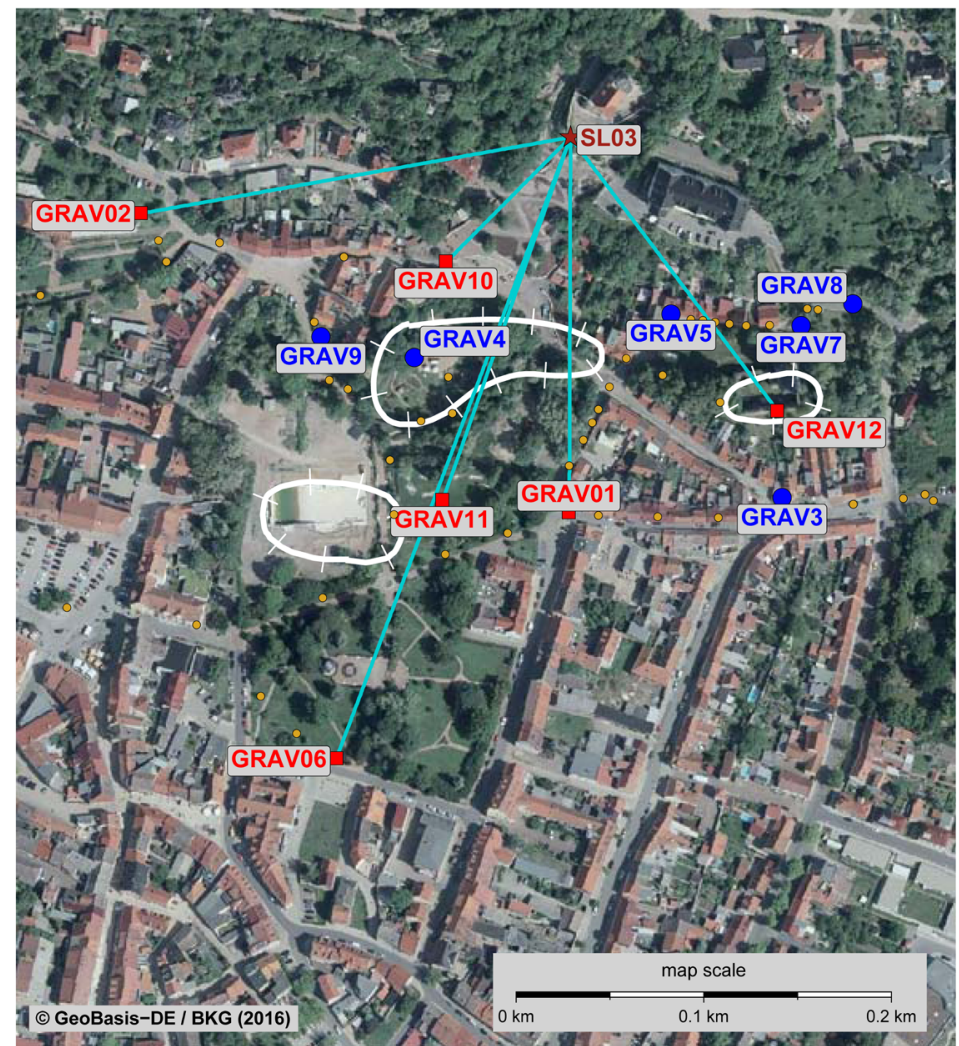

\title{
Bad Frankenhausen
}

\author{
(Thuringia, Germany)
}

N

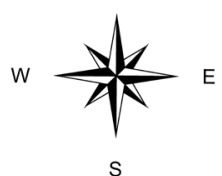

Legend

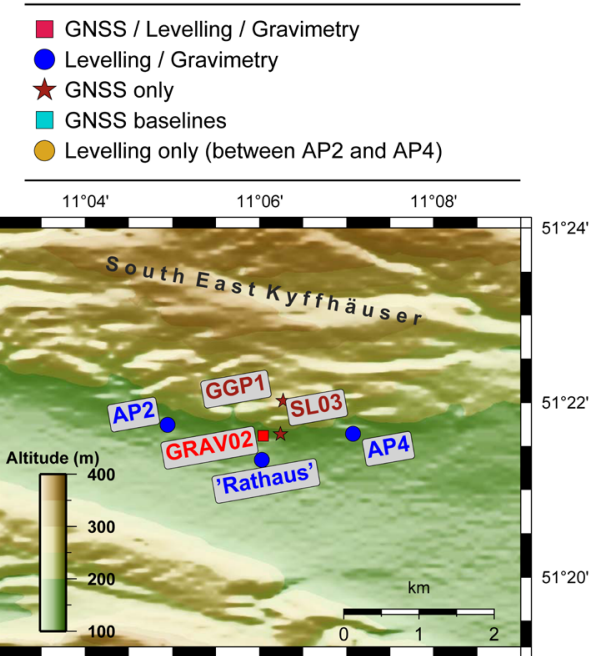

Figure 3. Field setup of geodetic monitoring network in Bad Frankenhausen.

(the satellite navigation system run by the Russian Federation) observations, are estimated to $0.8-1.5 \mathrm{~mm}$ for the horizontal component and to $0.8-3.5 \mathrm{~mm}$ for the vertical component, depending on the individual satellite sky distribution at each location (Kersten and Schön, personal communication, 2017).

A similar geodetic network is operated in the sinkhole area in Hamburg since two years. First results indicate that possible long-term trends due to leaching are often overlain by seasonal effects, most probably hydrogeological variations, which require correction models.

\section{Rock-Soil-Water Monitoring}

Soil parameters relevant to dissolution and speleogenesis are measured in the Münsterdorf area in northern Germany (c.f. Figure 2, located approximately half-way between Hamburg and Flintbek). The aim is to develop a concept integrating 3-D electric and electromagnetic tomography plus in situ probing like direct push (DP). Electrical conductivity and Cone Penetration Testing (CPT) were combined along a profile crossing a known and active sinkhole (Tippelt et al., 2017). A $2 \mathrm{~m}$ thick layer of increased conductivity is found at ca. $10 \mathrm{~m}$ depth consistently along the entire profile. This marks a compact clay layer at the transition from sand to till. Within the sinkhole area we observe with direct push profiling tools material of higher hydraulic conductivities above the chalk.

With spectral-induced polarization (SIP) the complex electrical resistivity at electrode strings in two boreholes (21 $\mathrm{m}$ and $23 \mathrm{~m}$ deep) of $5 \mathrm{~m}$ distance and at surface is monitored (Mai et al., 2017). The aim is to detect slight variations of electrical polarizability caused by the interaction of a time-dependent groundwater flow with soluble rock (chalk) and adjacent material, for instance due to changing pore water chemistry or rock texture. Equivalent to the CPT results, low values are visible for the sand-till transition at ca. $11 \mathrm{~m}$ depth. Here, continuous groundwater monitoring will help clarifying the hydrological situation over time, which initially shows a high groundwater pressure at $10-12 \mathrm{~m}$ depth.

\section{Collapse and Cavity Modelling}

Combined modelling and geophysical field work of a collapse sinkhole provides the numerical verification of a stepwise collapse from void growth at depth and chemical dissolution in the overburden (Kaufmann and Romanov, 2016). These processes may be aided by fractures and faults nearby (see above). 
Such mechanical interaction is constrained with the DEM (distinct element modeling) approach that is adapted for incrementally increasing dissolution zones and cavity growth (Al-Halbouni et al., 2017). The scenarios for Münsterdorf reveal for instance that a medium to high overburden strength is required to produce the mechanical collapse structure present. Low-strength scenarios yield a fully different structure.

Thus, the integration of soil properties describing the overburden in more detail puts local boundary conditions to such scenario calculation. According to a study of Grube et al. (2017), glacio-tectonics as influencing factor in areas of stronger karstification could be considered in the future, too.

\section{Feasibility and Recommendation}

The geophysical surveys, monitoring campaigns, and modelled scenarios provided so far by the integrated project SIMULTAN show both the feasibility and limits of approaches chosen.

In general, sinkhole processes with its end members subsidence and collapse develop with different rates and under a vast variety of boundary conditions. The scales to be evaluated range between $100 \mathrm{~m}$ to $\mathrm{cm}$, as well as decades and seconds (Figure 4). While geophysical imaging defines the structural layout in the subsurface, borehole monitoring and hydrological tools above cavities can help analyzing indicative changes in the subsurface. If it comes to collapse, the surface itself reacts latest but fastest.

With SIMULTAN we explore the applicability of a combination of methods and approaches dedicated to sinkhole early recognition. The reduction of seismic velocities and irregularities in wave-propagation behavior in the presence of subrosion are an important attribute that should be further evaluated with respect to its sensitivity and the technical implementation of it into a prediction tool. The calibration from geotechnical parameter studies is essential to develop monitoring concepts from invasive studies to non-invasive tools. The combination shown here seems to provide a first step towards this direction of geotechnical hazard assessment.

Reliable seismicity monitoring and especially the determination of the directivity of a subsurface signal is
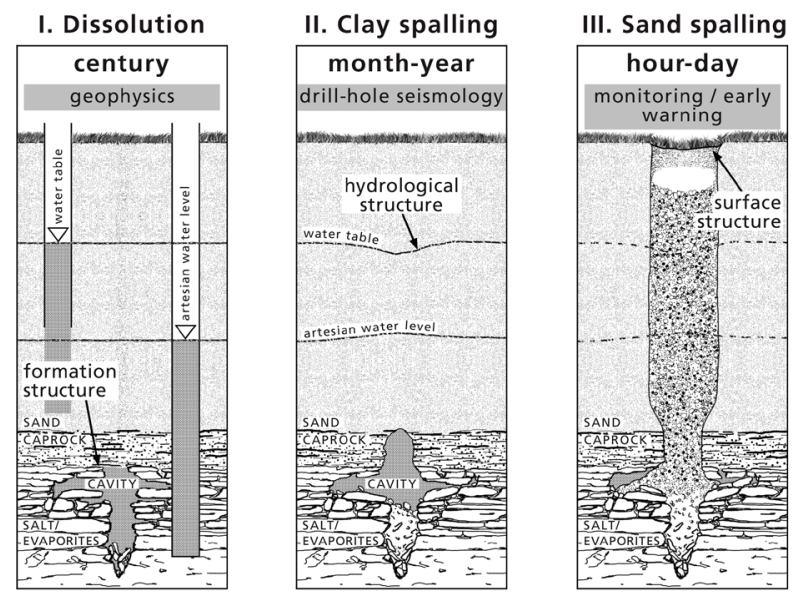

Figure 4. Scales to be considered in sinkhole research and adapted methodical layout.

challenging. Together with geodetic indicators for mass movements these can better be evaluated and possibly trends of cavity breakdown identified.

After a 2-year period of surveying only, we recommend that time-lapse and monitoring surveys shall be maintained during the next years to explore attribute sensitivity. InSAR monitoring should complement the geodetic monitoring setups, to better rate the sinkhole process and its stage in an area.

If we would use in turn the modelling results for prediction of parameter values that can be surveyed in the field, setups for field measurements with time-lapse or monitoring components should persist for at least five years to stabilize the prediction potential and reliability of trends. The approach here suggests acoustic emissions are related to microseismic monitoring of the seismic moment, interparticle forces may be used for stress field predictions, and strain simulation could be evidenced by extensometer measurements.

The combination of the above results with scenario modelling finally yields background and basic information for decision makers. Feeding these into a data base that encompasses also the quality control of specific methods and details provided, early warning in areas prone to enhanced sinkhole risk appears feasible.

\section{Acknowledgements}

We thank the geological surveys of Hamburg, SchleswigHolstein, and Thuringia for their support. This work is funded through the Ministry of Education and Research in Germany (grant 03G0843). 
Members of the SIMULTAN Research Group, listed by partnering institutions, are: GFZ Potsdam (coordinator, C. Krawczyk, D. Al-Halbouni, T. Dahm, S. Maghsoudi, E. Rivalta, R. Zaccharelli), LIAG Hannover (G. Gabriel, U. Polom, S. Tschache, A. Weise), Hannover University (T. Kersten, S. Schön, L. Timmen), Hamburg University (D. Becker), UFZ Leipzig (T. Tippelt, T. Vienken, U. Werban), FU Berlin (G. Kaufmann, D. Romanov), TU Berlin (F. Börner, F. Mai, C. Rücker), GGL (A. Schuck, U. Serfling), BUE (D. Bunge, A. Grube, J. Kröger, R. Taugs), LLUR (T. Liebsch-Dörschner, R. Kirsch, A. Omlin), TLUG (L. Katzschmann, I. Pustal, S. Schmidt).

\section{References}

Al-Halbouni D, Holohan EP, Taheri A, Dahm T. 2017. Distinct Element modeling of geophysical signatures during sinkhole collapse. Geophysical Research Abstracts 19: EGU2017-922-1.

Becker D, Dahm T, Scheider F. 2017. Detection and localization capability of an urban sinkhole monitoring network. Geophysical Research Abstracts 19: EGU2017-12905.

Dahm T, Heimann S, Bialowons W. 2011. A seismological investigation of shallow weak micro-earthquakes in the urban area of Hamburg city, Germany, and its possible relation to salt dissolution. Nat Hazards 58: 1111-1134. https:// doi.org/10.1007/s11069-011-9716-9.

Gebregziabher B. 2011. Environmental and engineering geophysical studies for sinkhole problems using seismic reflection, refraction tomography, electrical resistivity imaging, and joint inversions [PhD-thesis], Leibniz University Hannover.

Grube A, Grube F, Rickert BH, Strahl J. 2017. Eemian fossil caves and other karst structures in Cretaceous chalk and succeeding Quaternary sediments covering the salt structure KrempeLägerdorf (SW Schleswig-Holstein, North Germany). Z. Dt. Ges. Geowiss. 168 (2): 263-284.

Hunter JA, Burns RA, Good RL, Pullan SE, Pugin A, Crow H. 2010. Near-surface geophysical techniques for geohazards investigations: some Canadian Examples. The Leading Edge 29 (8): 964-977.

Katzschmann L, Pustal I, Schmidt S. 2015. Erdfälle geologische Grundlagen, Untersuchungsmethoden und Überwachungsmöglichkeiten erläutert an Fallbeispielen aus Thüringen. DGG-Kolloquium Sonderband Georisiken/Erdfälle I/2015, p. 3-4; ISSN 0947-1944.

Kersten T, Kobe M, Gabriel G, Timmen L, Schön S, Vogel D. 2017. Geodetic Monitoring of
Subrosion-Induced Subsidence Processes in Urban Areas - Concept and Status Report. Journal of Applied Geodesy 11 (1): 21-30. https://doi. org/10.1515/jag-2016-0029.

Kobe M, Gabriel G, Weise A, Krawczyk CM, Vogel D. 2017. Time-lapse gravity and levelling in the sinkhole-endangered urban area of Bad Frankenhausen, Germany. Geophysical Research Abstracts 19: EGU2017-17812.

Krawczyk CM, Dahm T: Charakterisierung und Überwachung von Salz-bezogenen Erdfällen in urbanen Gebieten [Internet]. 2011. White Paper, [Hannover]: LIAG; [updated] http://www.liaghannover.de.

Krawczyk CM, Polom U, Trabs S, Dahm D. 2012. Sinkholes in the city of Hamburg - New urban shear-wave reflection seismic system enables high-resolution imaging of subrosion structures. Journal of Applied Geophysics 78: 133-143. https://doi.org/10.1016/j.jappgeo.2011.02.003.

Krawczyk CM, Polom U, Beilecke T. 2013. Shear-wave reflection seismics as valuable tool for nearsurface urban applications. The Leading Edge 32 (3): 936-942.

Krawczyk CM, Polom U, Buness H. 2015. Geophysikalische Schlüsselparameter zur Überwachung von Erdfällen - Stand und Ziele der aktiven Seismik. DGG-Kolloquium Sonderband Georisiken/Erdfälle I/2015, p. 19-30; ISSN 0947-1944.

Mai F, Kirsch R, Rücker C, Börner F. 2017. Petrophysical effects during karstification. Geophysical Research Abstracts 19: EGU20179966.

McDonnell A, Loucks RG, Dooley T. 2007. Quantifying the origin and geometry of circular sag structures in northern Fort Worth Basin, Texas: Paleocave collapse, pull-apart fault systems or hydrothermal alteration?. AAPG Bulletin 91 (9): 1295-1318. https://doi.org/10.1306/05170706086.

Reuther C, Buurman N, Kühn D, Ohrnberger M, Dahm T, Scherbaum F. 2007. Erkundung des unterirdischen Raums der Metropolregion Hamburg: Das Projekt HADU (Hamburg-A Dynamic Underground). Geotechnik 30: 11-20.

Direct Push supported geotechnical and hydrogeological characterisation of an active sinkhole area.

Tippelt T, Vienken T Kirsch R, Dietrich P, Werban U. 2017. Direct Push supported geotechnical and hydrogeological characterization of an active sinkhole area. Geophysical Research Abstracts 19: EGU2017-16813. 
Tschache S, Wadas S, Polom U, Krawczyk CM. 2017. Investigation of sinkhole areas in Germany using 2D shear wave reflection seismics and zerooffset VSP. Geophysical Research Abstracts 19: EGU2017-3021.

Wadas SH, Buness H, Rochlitz R, Skiba P, Günther T, Grinat M, Tanner DC, Polom U, Krawczyk CM, Katzschmann L. in review. Multi-geophysical analysis of a subrosion-induced area of subsidence. Geophysics.

Waltham T, Bell F, Culshaw M. 2005. Sinkholes and subsidence. Heidelberg: Springer, 382 pp.

Wiederhold H, Gebregziabher B, Kirsch R. 2008. Geophysical investigation of a sinkhole feature in Schleswig-Holstein. Proceedings of the 12th European Meeting of EAGE. http://earthdoc.eage. org/detail.php?pubid=15063. 
322 NCKRI SYMPOSIUM 7 15TH SINKHOLE CONFERENCE 